\title{
Irrigation Infrastructure Management Requirements to Ensure Water Security for Impoverished Rural Populations under Climate Change Scenario
}

\author{
N.T.S. Wijesekera
}

\begin{abstract}
Climate change studies have come to maturity with the $4^{\text {th }}$ report of the Intergovernmental panel on Climate Change in 2007. Conclusions about temperature increases, rainfall variations, climate change relationships with evaporation etc., have more or less reached consensus. However climatologists have to fine tune climate models to refine the predictions. It is now necessary to assess the sustainability of the water and its surrounding environment with the anticipated climate changes. As at present in Sri Lanka there is minimum research attempting to link climate change impacts to infrastructure development, and there is none in the area of irrigation. Therefore it is necessary for countries like Sri Lanka where majority of the population depends on irrigated agriculture utilising a large number of small reservoirs, to ascertain the effect on its irrigation systems and identify the adaptation measures that should be implemented. A significant increase of water for irrigation sector would mean pressure on others which compete for water. If water is inadequate for irrigation then it would certainly lead to socio economic issues commencing from the farming community. In order to address these issues and to identify suitable adaptation options, the present research carried out spatially distributed irrigation water demand modelling to assess the administrative district wise requirements in the year 2025. Reservoir water balance modelling was carried out for four selected districts to study the adequacy of minor irrigation reservoirs. Present work describes the modelling efforts that incorporated system deterioration due to lack of maintenance superimposed on the climate changes. The study used irrigation department guidelines, published data and made rational assumptions to quantify the impacts on the irrigation systems. It was revealed that it is necessary for water and related infrastructure managers and engineers to incorporate suitable maintenance programs, and make significant efforts to improve the project efficiencies as climate change adaptation measures.
\end{abstract}

Keywords: Climate Change, Irrigation, Water Balance, Modelling, Spatially Distributed

\section{Introduction}

Reports of the Intergovernmental Panel on Climate Change 2007 (IPCC 2007a, 2007b) provides the decision makers with a much broader set of evidence on observed impacts coming from a larger number of field studies when compared with similar efforts in the past to idenfy climate changes, impacts and adaptation measures. However still there is much uncertainity about the potential climatic changes and impacts arising out of such changes. Some of the anticipated challenges from climatic change includes the changes to precipitation and its pattern, changes to irrigation demands, changes to soil moisture due to temperature variations, changes to quantities evaporated from irrigated lands and irrigation reservoirs. It is also said that it is possible to lose sensitive plant, fish and other living organisms that dwell in the irrigated area ecosystems.

Sri Lanka which is categorised as an agricultural country has Irrigation as the major water use sector. Out of an estimated surface water availability of $43,000 \mathrm{MCM}, 28 \%$ is for irrigation usage (ID 2003). In the Dry zone which consists of both the dry and the intermediate regions of the country covers approximately $75 \%$ of Sri Lanka (Imbulana,

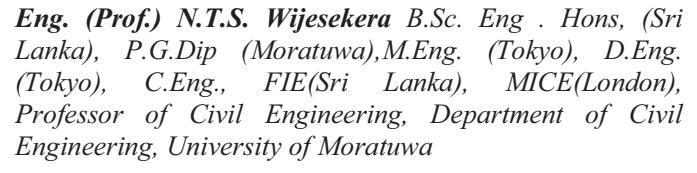


Wijesekera, and Neupane 2006). Irrigated agiculture in the Dry Zone is mainly with an extensive number of small and medium reservoirs that capture mosoonal rains. The schemes providing irrigation facilities for over 40 hetares are classified as major irrigation schemes while the rest are called minor irrigation schemes. There are approximately 533 Major Irrigation schemes under the Department of Irrigation serving an extent of about 340,000 hetares while there are nearly 25,000 minor irrigation schemes under the Department of Agrarian Services serving about 162,000 hetares(Survey 1988). These lands together with the Mahaweli project which was commenced with the target of providing irrigation facilities to 265,000 hetare of new land and 100,000 hetare of existing agricultural lands indicate the magnitude of irrigated agriculture in the country.

Sri Lanka's dry zone consists of a vast number of minor reservoirs called village irrigation tanks. According to Fernando (1982) there had been about 35,000 minor reservoirs in the island and more were being discovered. These reservoirs are the pivotal point of dry zone farming communities. They store water for irrigation, domestic and other environmental needs. Successive governments have allocated significant financial resources and effort to ensure the development and sustenance of these systems because of their importance to the dry zone farmers and the agricultural sector economy.

As such any adverse effect on Sri Lanka's irrigated agriculture and its irrigation reservoir systems would not only seriously affect the status of the farming community but also on the food security of the country. Climate change appears to affect the rainfall and the vegetation in the tropics. Therefore runoff into the reservoir systems would be affected. Climate change has been predicted to affect the pattern of rainfall and hence would change the timing of the receipt of reservoir inflows. Reservoir storage and especially those having high water spread area would be affected by increase of evaporation as a result of rising temperature. Magnitude and the temporal distribution of Irrigation demand would be affected due to possible changes to soil moisture as a result of increased evaporation, and due to any changes that would take place in the volume and timing of rainfall.

Apart from the effects of climate change, there is an ongoing concern that irrigation scheme maintenance has been given a secondary importance by the state. The present system of handing over of system maintenance to farmer organisations is relatively new and there is also a concern that the transfer of maintenance may lead to a further deterioration of the irrigation infrastructure. In case irrigation systems are deteriorating and country is faced with climate changes that have been predicted, then it is obvious that irrigation systems would be adversly affected. Most of the Dry zone reservoirs are of relatively small capacity, with high waterspread aeras, and presently cultivating maximum land aera that could be undertaken with the prevailing size of reservoir. It is crucial to identify whether these reservoirs could atleast guarantee the present cultivation extent, once the country is exposed to the climate changes.

The most important question of a water manager that requires an answer is "what is the magnitude of the effect due to climate change?". To answer this question fully, it is necessary to perform scheme level system analysis which incorporate the calculation of water yields and computation of reservoir water balance for water demands obtained through crop water requirement modelling. It is necessary to assess this problem very carefully because climate models have yet to provide estimates that are acceptable as reasonable inputs to small watersheds that are of the size associated with Sri Lankan irrigation reservoirs. There are also problems with other input data requirements such as elevation-capacity details for minor reservoirs, rainfall of the area, crop types and area of coverage, evaporation estimates etc. In this backdrop a water managers best option is not to wait until the data and predictions are of sufficient resolution, but to perform computations with available information to compute the order of magnitude of climate change impacts so that the selection of suitable adaptation alternatives could be done with scenario assessments. 
The present work carried out computations to identify irrigation water requirement under various climate and irrigation system performance situations while considering administrative districts as the spatial unit. In order to identify the effects of Climate Change scenario on available irrigation infrastructure, mainly the large number of small irrigation reservoirs, an assessment of the potential irrigable area under these reservoirs was also modelled using irrigation system analysis techniques.

\section{Background}

\subsection{Climate Change Predictions}

There is now higher confidence in projected patterns of warming and other regional-scale climate change features, including changes in wind patterns, precipitation and some aspects of extremes (IPCC 2007a). It is projected that crop yields could increase up to $20 \%$ in East and South-East Asia while they could decrease up to $30 \%$ in Central and South Asia by the mid-21 ${ }^{\text {st }}$ century. Taken together and considering the influence of rapid population growth and urbanisation, the risk of hunger is projected to remain very high in several developing countries (IPCC, 2007b). It is also stated with very high confidence that water resource in many small islands is likely to be seriously compromised. As a result of climate change they are likely to experience water stress and predictions show reduced rainfall in summer. Therefore it is unlikely that demand will be met during low rainfall periods. Increased rainfall in winter will be unlikely to compensate, due to a lack of storage and high runoff during storms (Parry et al 2007).

A study in South Africa has revealed that the increase of water surface evaporation, reduction of runoff due to drought, and increased deposition of silt due to change of rainfall and temperature is, much more in case of reservoir systems than for a run of river schemes (Mukheibir 2007). Mall et al (2006) reports that the hydrologic sensitivity studies for the Kosi Basin in India, to assess the projected land use and potential climate change scenarios has revealed that runoff increase was higher than precipitation increase in all the potential climate change scenarios applying cotemporary temperature. However the scenario of contemporary precipitation and a rise in temperature by $4^{\circ} \mathrm{C}$ caused a decrease in run-off by 2-8\%, depending upon the areas considered and the model used. The GCM simulations have revealed that projected increases in potential evaporation were largely due to increases in the vapour pressure deficit resulting from higher temperature (Mall et al 2006).

A study of seasonal and annual surface air temperature for 1ong term trend using data in India during 1901-82 for a well-distributed network of 73 stations has indicated a significant warming of $0.4^{\circ} \mathrm{C} / 100$ years in the mean annual temperatures for the country as a whole. In a subsequent study it had been found that all India mean annual temperature has shown significant warming trend of 0.05 ${ }^{\circ} \mathrm{C} / 10$ year during the period 1901-2003, the recent period 1971-2003 has seen a relatively accelerated warming of $0.22{ }^{\circ} \mathrm{C} / 10 \mathrm{yr}$, which is largely due to unprecedented warming during the last decade. The recent accelerated warming over India is manifested equally in day time and night time temperatures (Mall, Bhatla and Pandey (2007).

The impact of temperature on runoff has also been reported as substantial due to evapotranspiration. CCC (2009) cites a study conducted in Colarado River Basin by Nash and Gleick, where with no change in precipitation, a $2^{\circ} \mathrm{C}$ increase in temperature has shown a reduction of mean annual runoff by 4 to 12 percent. The change in runoff for a $4^{\circ} \mathrm{C}$ increase has been indicated between 9 and 21 percent and that for a temperature increase by $4^{\circ} \mathrm{C}$, precipitation would need to be increased by nearly 20 percent to maintain runoff at historical levels.

Nawaz, Adeloye, and Montaseri (1999) investigated the sensitivity of the storage-yield relationships of two multiple reservoir systems with respect to climate change through the incorporation of reservoir surface net evaporation flux and identified that for these Iranian catchments where evaporation is higher than the rainfall, there is a net additional outflow which leads to an increase in storage requirement for a given yield or would experience a reduction of the useable yield from a reservoir of a given capacity. The study also emphasizes the importance of having GCM outputs in the form of monthly percentage change in rainfall, temperature, 
radiation, humidity and wind speed for grid squares so that the rainfall and potential evaporation scenario in a monthly basis could be easily incorporated in the computations.

\subsection{Climate and Water Resources of Sri Lanka}

Sri Lanka located between latitudes $6^{\circ} \mathrm{N}$ and $10^{\circ} \mathrm{N}$ and longitudes $80^{\circ} \mathrm{E}$ and $82^{\circ} \mathrm{E}$ consists of an approximate land extent of 65,610 square kilometres. Being close to the equator, Sri Lanka experiences a climate of uniformly high temperatures but does not experience temperature extremes and it is stated that this is as a result of the surrounding ocean. Annual pan evaporation values indicate that there is a significant spatial variation consisting of values between 1900 and $795 \mathrm{~mm}$ per year. Average annual reference crop evapotranspiration at several stations in the country indicates a variation between $2.4 \mathrm{~mm} /$ day and $5.2 \mathrm{~mm} /$ day (ID 1999).

Rainfall in Sri Lanka is mainly governed by the North-East (December - February), and the South-West (May-September) monsoons. Rain during inter monsoonal periods are mainly due to local convections. Based on rainfall, Sri Lanka is commonly divided into three climatic zones namely the wet, intermediate and dry zone (Survey 1988) and the spatial variability varies significantly over time and a comparison of variations averaged over four 24 year periods (Wijesekera 2005) shows an indication of expanding dry area over time.

Though Irrigation sector is the major user, status of Sri Lanka appears to be at a much below consumption level when compared with neighbouring India which uses about $83 \%$ of available water for agriculture (Mall et al 2006). According to Imbulana, Wijesekera, and Neupane (2006), annual runoff is estimated to be around $35-40 \%$ of the annual rainfall and the values presented indicate that there are considerable variations in the individual values across rivers. Very low runoff ratios have been observed in most of the dry zone rivers; generally less than 35\%. According to a study by Amarasinghe, Mutuwatte and Sakthivadivel(1999) the per capita domestic withdrawal and the industrial withdrawal both in 1991 had amounted to about $1 \%$ which is much less than that indicated by the Department of Irrigation (ID 2003).

\subsection{Sri Lankan Climate Change Factors}

Modeling undertaken by the Sri Lankan Centre for Climate Change Studies, suggest that the changes in Sri Lanka broadly follow the regional expectations: (i) The regional temperature trends are played out in Sri Lanka. By 2100, the temperature increase during the southwest monsoon season (May to September) is anticipated to be $2.5^{\circ} \mathrm{C}$, whilst the northeast monsoon season (December to February) is expected to yield a temperature increase of $2.9{ }^{\circ} \mathrm{C}$, (ii) Rainfall is slightly different to the regional trend, with Sri Lanka's rainfall levels anticipated to increase in both summer and winter seasons. However, the rainfall change is expected to be greater during the southwest monsoons than northeast monsoons (iii) In both seasons rainfall and temperature is projected to increase with time, from 2025, 2050 to 2100, and (iv) Rainfall changes are also uneven across Sri Lanka - much greater increases are expected on the windward side of the central hills (PA 2009).

An analysis of trends in 15 climatic stations of Sri Lanka using 130 year data series, has indicated statistically significant temporal changes in Southwest - Monsoon - related precipitation at five of the stations, with three stations showing enhanced rainfall amounting to a total of $100 \mathrm{~mm} /$ month over the entire time interval and at two stations a decrease in rainfall with time amounting to a total of 150 $\mathrm{mm} / \mathrm{month}$. In addition, one station experienced a decrease of both First and Second Inter-monsoon rainfall over time with a total of $80 \mathrm{~mm} /$ month. Stations showing loss of rainfall are confined to higher elevation areas and those exhibiting enhanced rainfall are located in the lowlands confined to the southwestern sector of Sri Lanka. None of the stations had indicated any significant change in Northeast Monsoon precipitation through time (Malmgren et al 2003).

Analysis of long-term temperature data of the island has indicated an increasing trend of air temperature, particularly during the recent few decades. Mean annual air temperatures of Sri Lanka since 1930, in terms of the variation from the long-term mean has shown a 
warming trend during the recent few decades (Jayatillake et al 2005). Jayathilleka el al (2005) quoting, Fernando and Chandrapala (1992) and (Chandrapala 1996), reports that an analysis of temperature records of over 100 years at all the meteorological observation stations has indicated an increase in the mean air temperature of Sri Lanka in the order of 0.016 OC per Annum, during the period from 1961 to 1990.

Rainfall records of Sri Lanka has shown a high year to year variability. Mean Annual Rainfall fluctuations from 1880 till 2003, in terms of the departure from the long term mean has shown that the period from 1880 till 1970 has alternating dry and wet periods but a significant change to this behaviour is visible in the 30 year period from 1970 to 2000 where the average annual rainfall has reached below average for the entire period except for three years (Jayatillake et al 2005).

Comparison of the seasonal and annual rainfall values along with coefficient of variations for two recent 30 year reference periods of 1931-60 and 1961-90 has shown an overall decrease of $7 \%$ in the average annual rainfall with the change concentrated to the period from December to April. The major reduction has been during the North East monsoon while there had been no significant change in the second inter monsoon. This decrease has caused a shift in the demarcation of current Wet Zone, Dry Zone and the Intermediate Zone (Jayatillake et al 2005).

\subsection{Climate Predictions for Sri Lanka}

Future temperature and rainfall of Sri Lanka as computed by three AOGCMs forced with A2 SRES emission scenario together with observed values for the period 1961-90 as given in Jayathilaka et al (2005) show that the pattern of distribution has a high similarity with the HadCM3 indicating the highest values while the CGMS had the lowest. The three general circulation models that had been used were, CGCM (Canadian General Circulation Model), HadCM3 (Hadley Centre General Circulation Model - Version 3), and CSIRO (Commonwealth Scientific and Industrial Research Organization General Circulation Model). Spatial distributions presented by Jayathilaka et al (2005) clearly indicates that the predictions in the year 2050 presents a significant expansion of the dry areas of the country thereby suggesting a significant pressure on the water resources and the need to effect suitable adaptation measures through systematic studies.

\section{Approach and Methodology}

\subsection{Irrigation Demand Modelling}

Literature points to a general decline of Sri Lanka's rainfall and an increase in temperature. Increase in temperature results in an increase in evaporation and evapotranspiration. A selected crop having a specific crop water requirement depending on its crop development stage would require an amount of water as irrigation demand, given the land preparation requirements, farm losses and project efficiencies. An irrigation water demand model with a monthly computational time step was developed according to the ID(1984). Model computations were carried out considering the administrative districts as the spatial unit for aggregation. Governing equations used for the computations are as follows.

$$
\begin{aligned}
& (\mathrm{FWR})_{\mathrm{t}}=(\mathrm{LP})_{\mathrm{t}}+\left(\mathrm{Et}_{\mathrm{c}}\right)_{\mathrm{t}}+(\mathrm{FL})_{\mathrm{t}} \text {----- }(1) \\
& (\mathrm{FIR})_{\mathrm{t}}=(\mathrm{FWR})_{\mathrm{t}}-(\mathrm{ER})_{\mathrm{t}} \\
& (\mathrm{ID})_{\mathrm{t}}=(\mathrm{FIR})_{\mathrm{t}} / \eta
\end{aligned}
$$

In these equations, $\mathrm{t}$ is the considered time step for computations and $\mathrm{n}$ is the number of time steps per period. LP is the water requirement for land preparation, ETc is the water requirement for crop evapotranspiration, and FL is the water required to compensate for farm losses. FWR is the field water requirement, ER is the effective rainfall, FIR is the field irrigation requirement, ID is the irrigation demand and $\eta$ is the project efficiency.

Evapotranspiration and rainfall were taken as spatially distributed inputs for model computations. Crop types selected by farmers for each season, land preparation water requirements, farm loses and the project efficiency were assumed as uniform inputs for all spatial units since no spatially distributed data on crop types, planting dates etc., were 
available. Also it was felt that by keeping constant values for these would enable an easy analysis of water requirement values through the model.

Irrigated area in each spatial extent had two types of cultivations as paddy or other field crops (OFCs). Irrespective of the crop type, period of irrigation for each land unit was assumed as 105 days for the Yala season (SW monsoon) and 135 days for the Maha season (NE monsoon). In the OFC cultivation area, it was assumed that the same crop was cultivated and this crop was taken as Chillies. The values of crop growth stages and crop factors given in the Irrigation Department guidelines were used for the computation of temporally distributed evapotranspiration requirements for each unit area.

Land preparation for all spatial units and for the Maha and Yala seasons was taken to commence in the months of October and May respectively. In order to optimise the water resources infrastructure, the commonly incorporated three stagger system was assumed as the cultivation pattern in each irrigated area.

In this study the monthly $75 \%$ probable rainfall data given in the ID (1984) were taken as the base data for the representation of prevailing situation. Year 2025 was taken as the comparison time line because of the availability of GCM predictions. Rate of change of annual rainfall computed using the observed averages of $1961-90$ period and CSIRO predictions in Jayathilleka et al (2005) was assumed equal to rate of change of rainfall values in ID (1984). This assumes that the $75 \%$ probable rainfall reported in 1984 could be taken as that for the period between 1969 -1990. Rate of change of modelled values for the year 2025 when compared with the averaged 1961-90 values, indicated a decline in rainfall except in seven districts.

Two future scenarios pertaining to monthly rainfall distribution was considered for irrigation demand modelling. One was that the rate of change of annual rainfall was uniform over each month of the year. The other was that, the assumed rate of change resulted due to an increase of peak monthly rainfall by $20 \%$ while the rest of the months had an apportioned rate of change resulting in the same average observed in the annual value. Value of $20 \%$ was taken as a comparative figure after carrying out a few trial and error computations. The second case was developed as an attempt to consider the climate change predictions which indicated higher rain during rainy periods, and drier dry months. Agro ecological region rainfall values (ID 1984) were aggregated to the administrative district boundaries by calculating the area weighted average for each district. Irrigation Department ID(1984) values of Pan evaporation were spatially distributed using Thiessen (Voronoi) polygons and then computing area weighted average for each district. Irrigation department recommended pan coefficient of 0.8 was used for water demand modelling.

Literature survey identified that affecting a $2 \%$ change in temperature while keeping all other parameters constant would give rise to a change in runoff by $4-12 \%$ and this was assumed as a result of the change in evaporation. Accordingly, the present work assumed that a 2 degree increase of temperature would affect an increase of $8 \%$ in evaporation. This rate was used with the observed trend of temperature rise that had been reported for Sri Lanka by Jayathilleka et al (2005). Spatial values of evaporation computed using values from ID (1984) were uniformly increased to cater to the entire increase during the 34 year period reaching year 2025. Irrigation water requirement computations were based on the Paddy and OFC cultivation area and other appropriate details per district as reported in the Amarasinghe, Muthuwatte and Sakthivadivel (1999).

\subsubsection{Scenario Identification}

Irrigation water demand modelling considered the following five scenarios to compare the water resources management requirements in case of climate change. As the base case the model used a project efficiency value of $70 \%$ for all districts.

\section{Base Scenario:}

Computation of the irrigation water requirement for the base year which is considered as 1991, having parameters and inputs as given in the irrigation department guidelines or in the reported 
literature and having an overall irrigation project efficiency of $70 \%$ throughout the country.

Scenario 1: SC1_70 (Temperature Rise and Uniform Variation of Rain)

Computation of the irrigation water requirement in the year 2025, with the predicted annual rainfall change keeping in line with the CSIRO model. The change to the annual rainfall value of a particular spatial entity is effected uniformly over each month of the year. Change of evaporation is based on the temperature rise that had been observed in the past data. Project efficiency is $70 \%$.

Scenario 2: SC2_70 (Temperature Rise and Rainfall has a Higher Peak)

Computation of the irrigation water requirement under the same conditions as in the Scenario 1 but without effecting a uniform inter annual variation, apportioned the rainfall to have a higher percentage of rain in the peak rain month and less rain in the other months.

Scenario 3: SC3_70 (Temperature Rise, Uniform Variation of Rain, Increase of Grown Area)

Computation of the irrigation water requirement under the same conditions as in Scenario 1 but for the irrigation land area to increase in order to reflect ongoing food cultivation drives. This scenario assumes a $5 \%$ increase of the paddy area and a $2 \%$ increase in the OFC extents.

Scenario 4: SC4_65 (Temperature Rise, Uniform Variation of Rain, Increase of Grown Area, Reduced Project Efficiency)

Computation of the irrigation water requirement under the same conditions as in Scenario 3 incorporating an overall project efficiency deterioration from $70 \%$ to $65 \%$.

Scenario 5: SC5_75 (Temperature Rise, Uniform Variation of Rain, Increase of Grown Area, Increased Project Efficiency)

Computation of the irrigation water requirement under the same conditions as in Scenario 3 incorporating an overall project efficiency improvement from $70 \%$ to $75 \%$.
District wise water demand for irrigation in each season was computed relative to the baseline year. In each District, change in the water demand was compared with the corresponding change in rainfall for both Maha and Yala seasons.

\subsection{Irrigation Infrastructure for Modelling}

In case of water resource utilisation, predictions due to climate change would give rise to additional burdens on the available infrastructure. Capacities of the prevailing canal systems and reservoirs pertaining to irrigation systems would require to be assessed. This is necessary to check the capacity of the reservoirs to store the system inflows even with a changed quantity and a variation in the timing while there is a change in system outflow with a change in the value of evapotranspiration and changed effective rainfall value. In other words to perform a check of the system water balance incorporating changes to inputs and outputs due to climate change, while keeping the maximum storage of the system unchanged. In case of water supply systems too it is essential to assess water intake capacities, storage sizes and transmission line system adequacies.

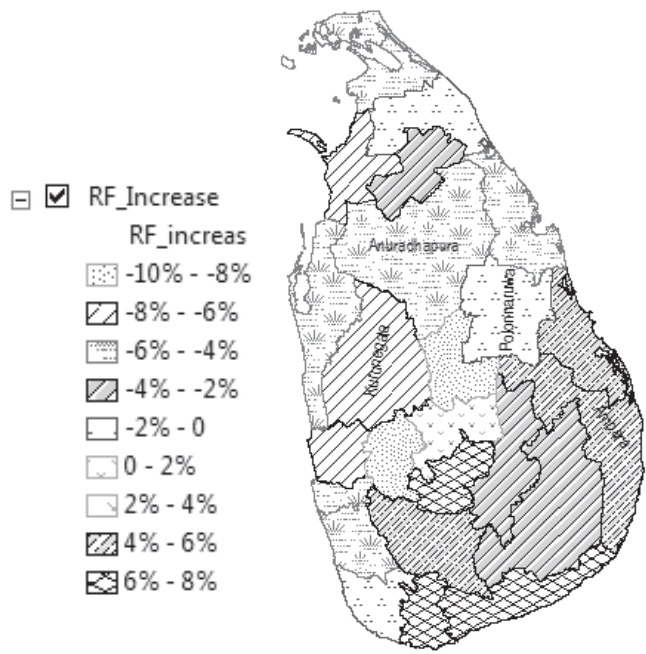

Figure 1- Spatial Distribution of the Selected Districts and the Anticipated Rainfall Change in 2025 when compared to the Base Year

In this study, a minor reservoir of a typical terrain in the Dry Zone was considered at four 
selected districts and was subjected to various climatic scenarios corresponding to each of the districts. Consideration of a typical reservoir for the present work is felt adequate for a comparative assessment of the climate change impact on a per reservoir basis for the selected districts. Though it was more realistic to incorporate actual reservoir data from each district, due to lack of data the present study assumed that the three districts have a similar terrain and then used a reservoir bed survey dataset of a reservoir in the Anuradhapura district as the typical dataset. During water balance modelling, minor adjustments were incorporated to the reservoir dimensions and irrigable areas of the base case scenario to ensure realistic outputs. Anuradhapura, Ampara, Pollonnaruwa and Kurunegala, which significantly contribute to the paddy cultivation of Sri Lanka were the selected districts. Figure 1 shows the spatial distribution of selected districts and anticipated rainfall change from the base year.

\subsubsection{Reservoir Water Balance Modelling}

Irrigable area under the reservoir at each district was modelled for Maha and Yala seasons considering changes to the inflow from rainfall, evaporation on the reservoir water, irrigation demand due to changes in crop water requirements etc. Model computations were based on the water balance of the reservoir system described in the guidelines of Irrigation Department (ID 1984). Governing equation for water balance of reservoir system is as shown in Equation (5).

$$
\mathrm{I}_{\mathrm{t}}-\left(\mathrm{E}_{\mathrm{t}}+\mathrm{Se}_{\mathrm{i}}+\mathrm{Sp}_{\mathrm{t}}+\mathrm{D}_{\mathrm{t}}\right)=\mathrm{S}_{\mathrm{t}}-\mathrm{S}_{\mathrm{t}-1-----}(5)
$$

In this equation $t$ is the time step which was considered as one month, I is the Inflow, E is the evaporation from the water surface, Se is the seepage from the reservoir bed, $S p$ is the spillage from the reservoir, D is the irrigation demand, $S$ is the storage of the reservoir.

Water balance under the base scenario, and scenarios SC1-70, SC2-70, SC2-65, SC2-75 were carried out to compute the feasible irrigable area for Maha and Yala Seasons. Field irrigation requirements and irrigation demand per unit area were computed through the irrigation demand model where district wise irrigation demands were determined. Since this study was to identify possible irrigation extents, the scenarios SC3, SC4 and SC5 were not applicable. Instead only the sensitivity of irrigable area under various project efficiency values was studied.

Since paddy is the major crop grown in the dry zone of Sri Lanka, model computations were confined to the assumption that under the irrigation reservoir, only paddy is grown during Maha and Yala seasons.

\subsubsection{Rate of change of Rainfall}

Results reported by Jayathillika et al (2005) indicated the future annual rainfall pertaining to administrative districts. Increases indicated values between $0.8-8.3 \%$, while the decreases showed values from $0.7-10.7 \%$. Rate of change of rainfall computed using the observed and GCM predicted values were then applied to the $75 \%$ probable rainfall values to calculate model inputs.

\subsubsection{Monthly Rainfall Distribution}

Irrigation Demand and Reservoir water balance modelling incorporated three rainfall distributions at each district for scenario comparisons. The base line (1991), uniform distribution of annual increase or decrease (SC1), and a distribution with an increased peak (SC2) for Ampara District is shown in Figure 2 to illustrate a typical model inputs.

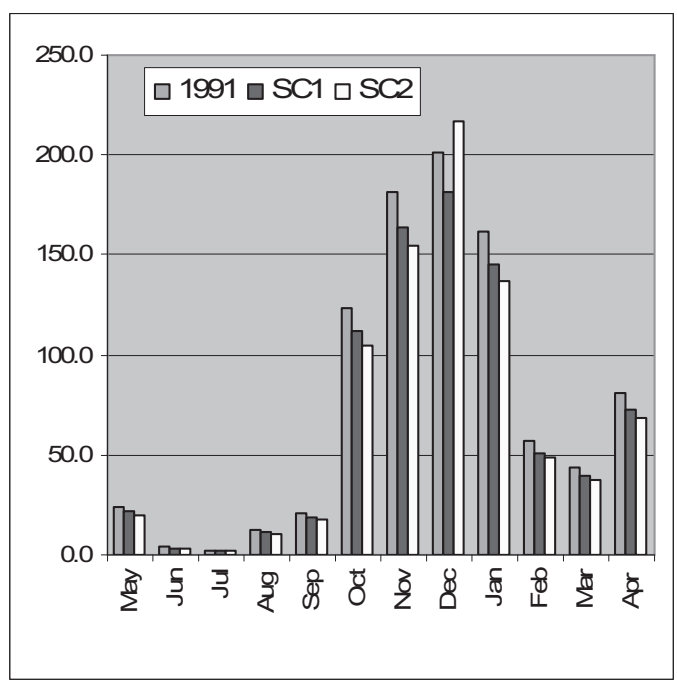

Figure 2- 75\% Probable Rainfall (mm/month) for 1991 and Future Rainfall Scenario - Ampara District Sri Lanka 


\section{Results and Discussion}

\subsection{Change in Irrigation Demand}

Percentage change in district wise seasonal water demand for irrigation was computed relative to the baseline year (Figure 3) in order to assess the seasonal variations as a result of anticipated climate changes. Furthermore, model computations enabled the identification of change in water demand relative to the corresponding change in the rainfall (Figure 4) for each irrigation season. In Figure 4 the $X$ axis corresponds to the change in rainfall and $\mathrm{Y}$ axis corresponds to the Change in Irrigation Demand. Each point represents an administrative district.

\subsubsection{Maha Season}

Model computations indicated that during Maha season, for scenario 1 and 2, the range of increase in water demand was 5\%. (Figure 3). Maha season being the rainy period, an increase in peak runoff affected by rainfall scenario 2 resulted positively for most districts. However an increase of irrigated area (SC3) indicated a marked rise in the water demand. Together with a deterioration of delivery efficiency, this increase in water demand in several districts rose to values in the range of $10-15 \%$. In case of an efficiency improvement to a $75 \%$ showed that it is possible to negate the negative effects that arose from a decrease of rainfall and an increase of evaporation.

Figure 4 showed an expected behaviour where a reduction of rainfall would lead to an increase of Irrigation Demand. It could be noted that in case of scenario 1 and 2, the increase of water demand was less than the decrease in rainfall and this could be due to the high water availability in the Maha season. However as the irrigation area gets increased and when the irrigation infrastructure gets deteriorated then this advantage gets diminished.

\subsubsection{Yala Season}

In case of Yala season, model results (Figure 3) shows a higher water demand for scenario 1 and 2 in districts such as Colombo having relatively low irrigated agriculture. Similar to Maha season, the Scenario 3 and 4 show the

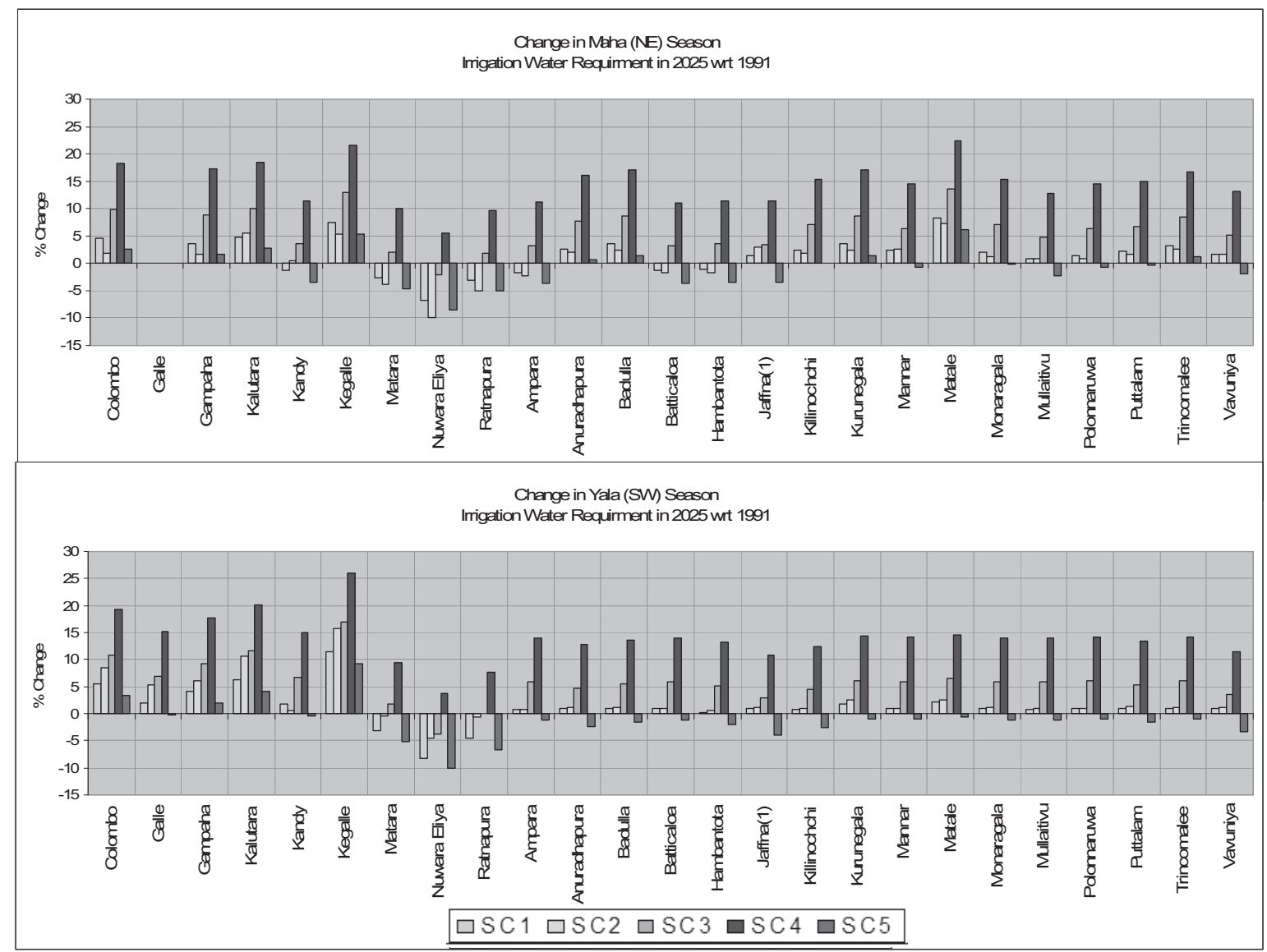

Figure 3- Comparison of Relative District wise Irrigation Demand Change for Each Climate Change Scenario 
impact of climate effects together with an irrigated area expansion and a lowering of delivery efficiency. The scenario 3 indicated a rise of water demand in several districts to values between $10-17 \%$. As in the Maha season, an improvement on the efficiency would be able to counter the climate change effects during the Yala Season too.

Model results in Figure 4 for Yala season, indicate that the changes of rainfall does not show a clear relationship to the changes reflected in the irrigation Demand values. Though the general tendency could be seen in case of Scenario 3 and 4, the response is

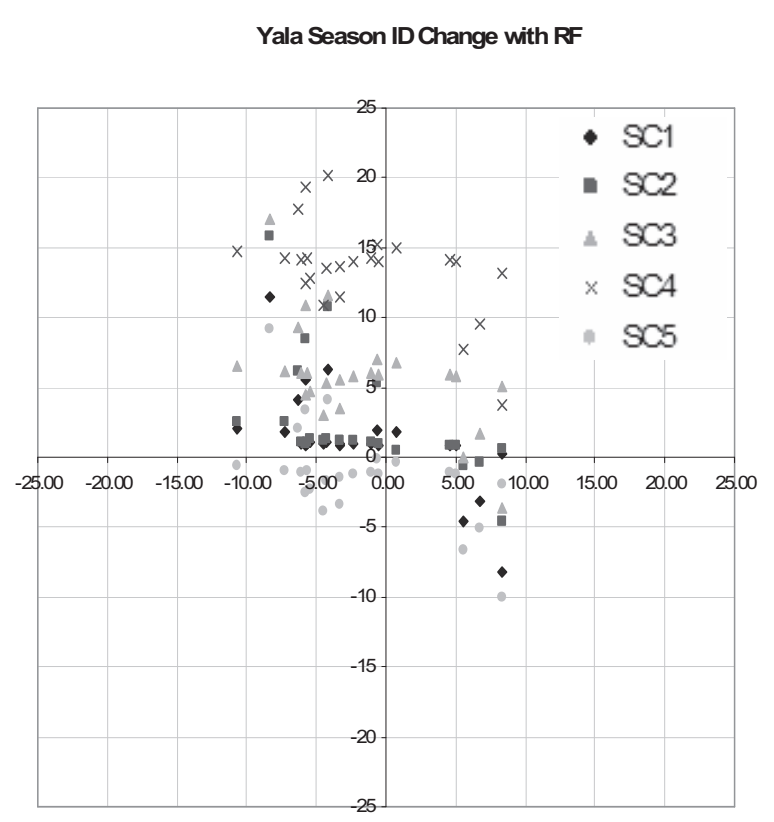

Maha Season ID Change with RF

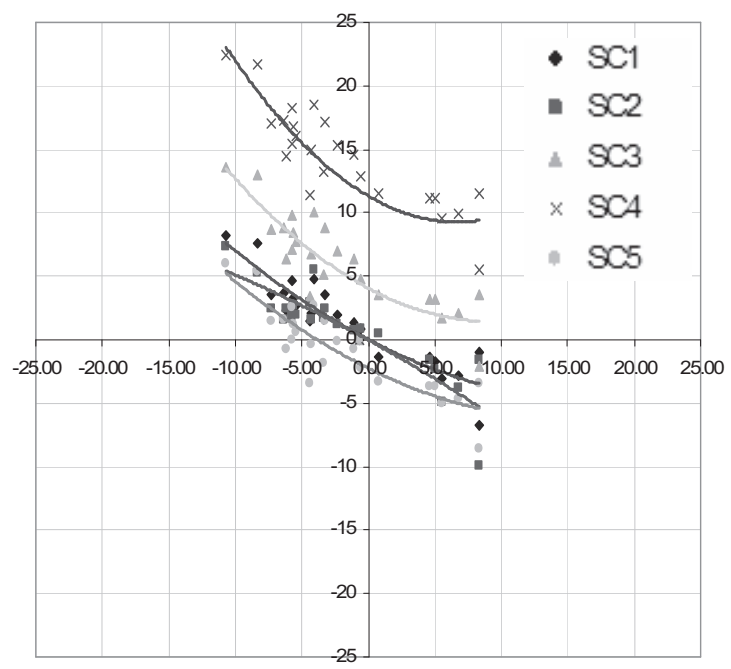

Figure 4- Comparison of Rainfall Change and the Corresponding Irrigation Demand Change for each Spatial Unit and Each Climate Change insensitive for smaller changes of rainfall. This clearly reflects the behaviour of the regions with very low rainfall where the reductions do not have a significant impact on the irrigation demand. Moreover the very low rainfalls and very high rainfalls are looked after in the demand modelling through the incorporation of threshold values for effective rainfall as given in the Irrigation Department Guidelines. Therefore simple relationships or conclusions cannot be identified when the system inputs are close to the thresholds or beyond the thresholds.

\subsection{Change in Cultivation Extent}

Rates of change of possible cultivation area for Maha and Yala seasons under a reservoir and for each scenario with respect to the baseline are shown in Figure 5.

Model results show that even at a constant efficiency level, the climate scenario 1 and 2,

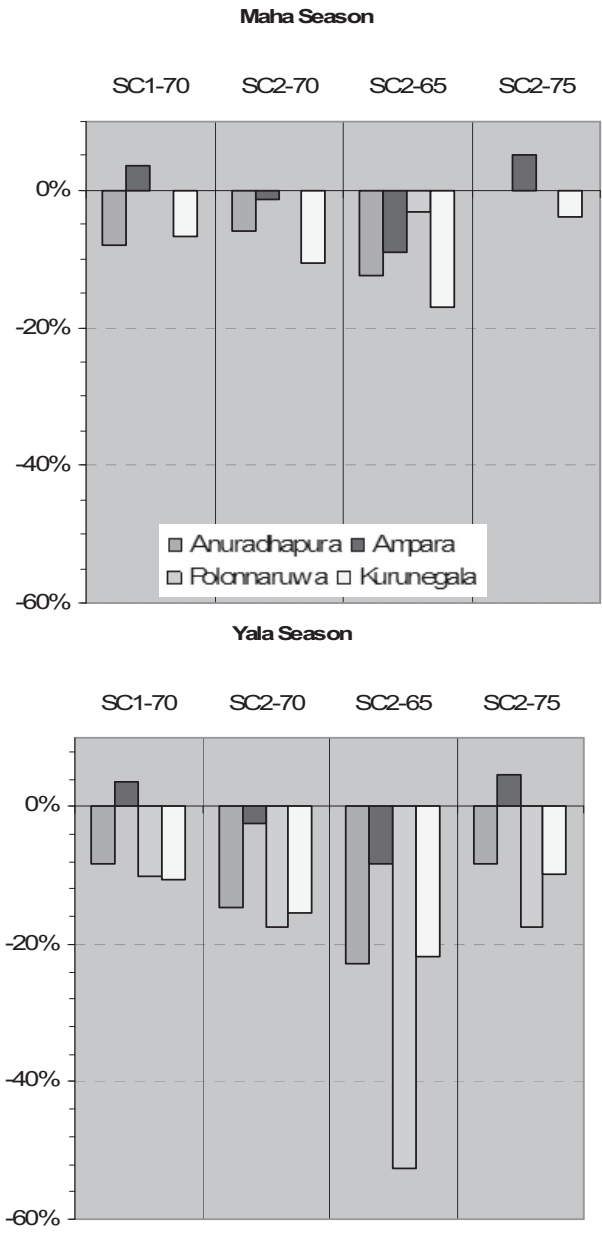

Figure 5 - Variation of Maha and Yala Irrigable Area \% Under a Minor Irrigation Reservoir 
would create a significant loss of irrigable area under each tank in case of a climate change resulting a reduction of rainfall. In the Ampara district where the rainfall is expected to increase with respect to 1991, the Scenario 1 would support the functioning of the system even with the possibility of enhancing the extent under cultivation. However when the rainfall is concentrated to the wet month the reservoir system does not receive a benefit as spillage occurs in most of the occasions. Under such extreme value changes, it is noted that the Yala season reduction of extent is greater. Scenario 4 indicates that the deterioration of the delivery system or having a poor delivery system and having a poor management system would aggravate the situation. Maximum possible irrigable area under each reservoir computed through reservoir water balance, were converted to percentage change in area in order to obtain district wise land extents. Literature reported Maha and Yala paddy cultivation extents (Amarasinghe, Mutuwatte and Sakthivadivel1999) in each selected district were used with a proportionality relationship to compute the district wise irrigable area change due to climate change scenario (Figure 6).

These model results for Maha and Yala show

Maha Season (Ha)
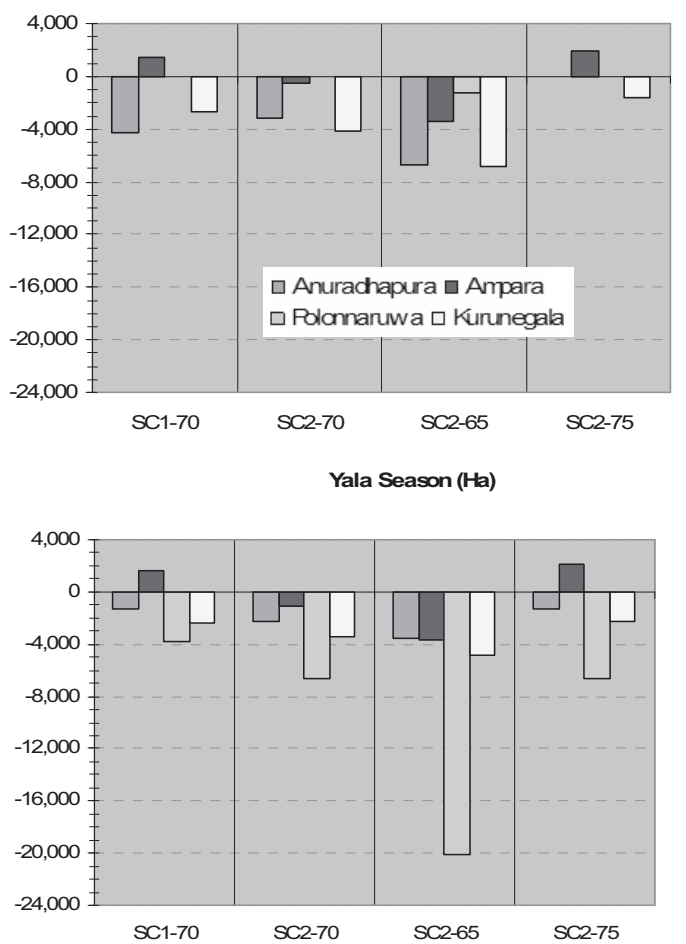

Figure 6 - Estimate of Maha and Yala Irrigable Area Variation in $\mathrm{Ha}$ for Each Selected District that there would be a very significant impact on the paddy farmers as a result of climate change and this would reach very high values in case of poor management of reservoir systems.

\subsection{Conclusive Directions and Improvements}

A. The study indicates that the climate change scenario has a significant impact on the water requirement for irrigation purposes. This would burden or stress the environmental flows and also exert pressure on the irrigation infrastructure either requiring expansions or forcing to function closer to their design limits.

B. This situation would aggravate with irrigated area expansions as a result of cultivation drives which are forced by high food prices in the local market, high import bills for imported food items and the growth of population.

C. The present study showed that neglecting the irrigation systems thereby decreasing the efficiencies would significantly increase the water requirements which would lead to more expenditure on infrastructure rehabilitation and new system expansions. As such it is of extreme importance to effect suitable management interventions in order to identify and mitigate the climate change impacts. Capacity building, effecting suitable maintenance programmes, identification of water allocations, establishing suitable data collection programmes, are several options among other IWRM alternatives for mitigating the climate change impacts.

D. In this study several assumptions such as a project efficiency value without spatial or temporal variation, a common farm loss for all districts, a fixed coefficient for intra annual rainfall distribution were incorporated. Also the paddy type cultivated in each season, and the OFCs used for modelling were uniform for all districts. Though these assumptions provide results to make national level decision making in the present day context where no research has been done to link climate change impacts to irrigation 
infrastructure, studies similar to the one described in this work should be carried out with more specific data and in greater detail in order to identify scheme level results with regards to the optimum paddy or OFC varieties, land areas to be irrigated, and cultivation calendars incorporating the spatial variation of rain and evaporation.

E. The modelling efforts in this work assessed the probable impacts of reservoir limitations as a result of climate change through a study of four districts which would experience declining as well as increasing rainfalls. Even with an increase of rainfall, scenario 2 and 3 indicated that Ampara district would experience difficulties with a reduction in cultivation area. In case of Polonnaruwa the reduction of area with scenario 3 was the highest at $53 \%$ in Yala and the lowest at 3\% in Maha. Therefore study on typical minor reservoirs and possible effects on the irrigable area reveals that even if there is adequate water resources in the country to cope with the climate change scenario at the present or a moderate level of development, there could be a major problem due to the constraints of minor reservoirs due to capacity limitations. Accordingly it is very important for managers and policy level decision makers to effect early adaptation actions to strengthen the water resources management in the irrigation sector and especially in minor tank cascade systems.

F. The scenario identifications selected typical values of project efficiencies. In case of better approximations, the computer models used for irrigation demand computations and system water balance, provide options for a decision maker. However, detailed studies should incorporate the spatial variation of commencement dates, project efficiencies, and crop types so that better out puts desired at project level could be computed for the incorporation of management interventions to mitigated climate change impacts.

G. In the absence of historical rainfall records to assess the best suited model, the CSIRO model outputs which provided with moderate values was chosen for the comparative assessment in the present work. In case of identifying a reliable climate predictions which is of paramount importance for mitigation or adaptation activities, it is important for Sri Lanka to use past data for the comparison of actual values with modelled climate predications in order to establish relationships. Since these relationships would facilitate more reliable outputs, studies pertaining to such should be initiated at the earliest.

\section{Conclusions}

1. A spatially distributed seasonal water resources analysis enabled the identification of district wise climate change impacts on irrigation water demand and the impact on the cultivable extents facilitating the decision maker to select appropriate adaptation measures.

2. The modelling clearly indicated the order of magnitude of adverse effects that may arise due to lack of maintenance of irrigation infrastructure combined with predicted climate change thereby emphasising the importance of effective and efficient water and associated infrastructure management for a sustainable socio-economic environment.

3. It is necessary to carryout individual irrigation scheme or reservoir system based modelling with suitable spatially and temporally distributed datasets for incorporation of location specific adaptation measures.

4. Climate change impacts along with a deterioration of irrigation system efficiency from $70 \%$ to $65 \%$, and pressured by increase of cultivation extents, would increase water demands in both seasons reaching values as high as $15-17 \%$ at some districts.

5. Impact of reservoir storage limitations on the anticipated climate change scenario at the studied locations, identified that with a deteriorating system efficiency from $70 \%$ to $65 \%$ would lead to reduction in command areas reaching to values of $17 \%$ in Maha and 53\% in Yala. 


\section{References}

1. Amarasinghe, U.A., Mutuwatte L. and Sakthivadivel, R., "Water Scarcity Variations within a Country: A Case Study of Sri Lanka", Research Report 32, International "Water Management Institute, ISBN 92-9090-383-X, ISSN 10260862, Colombo, Sri Lanka,1999.

2. Evaporation and Transpiration, Climate Change Clearinghouse, Water Research Foundation,http://www.theclimatechang eclearin ghouse.org/-HydrologicEffects, Visited in Dec. 2009

3. Fernando, A.D.N., The Ancient Hydraulic Civilistion of Sri Lanka in Relation to Naatural Resources, Journal of the Sri Lanka Branch of the Royal Asiatic Society, Reid Avenue, Colombo 7, 1982

4. Fernando, T.K. and Chandrapala, L., "Global Warming and Rainfall Variability - The Sri Lankan Situation.", Proceedings of $5^{\text {th }}$ International Meeting on Statistical Climatology, Toronto, Canada, 1992

5. Ponrajah, A. J, P., Design of Irrigion Headworks for Small Catchments, $2^{\text {nd }}$ Edition, Irrigation Department, Colombo, Sri Lanka, 1984

6. ID 2003 Irrigation Department, Water Statistics handbook, Department of Irrigation, Colombo,Sri Lanka, 2003

7. Imbulana, K.A.U.S., Wijesekera, N.T.S. and Neupane B.R., (eds.), Sri Lanka National Water Development Report, MAI\&MD, UNWWAP, UNESCO and University of Moratuwa, ISBN 955 -8395-01 -3, Sri Lanka, Paris and New Delhi, 2006

8. Solomon, S., Qin, D., Manning, M., Chen, Z., Marquis, M., Averyt, K.B., Tignor M., and Miller, H.L., (eds.)., Summary for Policymakers. In: Climate Change 2007: The Physical Science Basis. Contribution of Working Group I to the Fourth Assessment Report of the Intergovernmental Panel on Climate Change, Cambridge University Press, Cambridge, United Kingdom and New York, NY, USA.

9. Parry, M.L., Canziani, O.F., Palutikof, J.P., Vander Linden, P.J., and Hanson, C.E., Eds., Summary for Policymakers. In: Climate Change 2007: Impacts, Adaptation and Vulnerability. Contribution of Working Group II to the Fourth Assessment Report of the Intergovernmental Panel on Climate Change,
Cambridge University Press, Cambridge, UK, 7-22.

10. Jayatillake, H.M., Chandrapala, L. Basnayake, B.R.S.B. and Dharmaratne, G.H.P. "Water Resources and Climate Change" Proceedings Workshop on Sri Lanka National Water Development Report, 2005.

11. Jayatillake, H.M., Chandrapala L. Basnayake B.R.S.B., Dharmaratne G.H.P., "Water Resources and Climate Change", Proceedings of the Preparatory Workshop on Sri Lanka National Water Development Project, 2005.

12. Jayatillake, H.M., Chandrapala, L., Basnayake, B.R.S.B. and Dharmaratne, G.H.P., "Water Resources and Climate Change" Proceedings Workshop on Sri Lanka National Water Development Report, eds. Wijesekera, N.T.S., Imbulana, K.A.U.S, and Neupane, B.,World Water Assessment Programme. Paris, France, 2005

13. Mall, R. K, Gupta Akhilesh, Singh Ranjeet, Singh, R. S. and. Rathore, L. S., "Water Resources and Climate Change: An Indian Perspective", Current Science, Vol. 90, No. 12, 25, June 2006.

14. Mall, R.K., Bhatla, R., and Pandey, S.N., "Water Resources in India and Impact of Climate Change", Julvigyun Sameekshu, Vol. 22, 2007.

15. Bjorn Malmgren, Ranatunge Hulugalla, Yousay Hayashib and Takehiko Mikami, "Precipitation Trends In Sri Lanka Since the 1870s and Relationships to El NiNoSouthern Oscillation", International Journal of Climatology Int. J. Climatology. 23: 12351252, Published Online in Wiley Interscience, 2003.

16. Mukheibir, P., "Possible Climate Change Impacts on large Hydroelectricity, Schemes in Southern Africa", Journal of Energy in Southern Africa, Vol 18 No 1, February 2007

17. Nawaz, N. R., Adeloye, A. J., and Montaseri, M.,"The Impact of Climate Change on Storage-Yield Curves for MultiReservoir Systems", Nordic Hydrology, 30 (2), 1999, 129-146

18. Practical Action, Promoting Adaptation to Climate Change in Sri Lanka, A briefing for Government Advisors and 
Development Practitioners, http://practicalaction.org/advocacy/docs /advocacy/Adaptation_to_climate_chang e_Sri_Lanka.pdf, visited in December 2009

19. Parry, M.L., Canziani, O., F Palutikof, J.P., vander Linden P.J., and Hanson, C.E., Eds., "Technical Summary. Climate Change 2007: Impacts, Adaptation and Vulnerability. Contribution of Working Group II to the Fourth Assessment", Report of the Intergovernmental Panel on Climate Change, Cambridge University Press, Cambridge, UK, 23-78.

20. Survey 1988, The National Atlas of Sri Lanka Agro Ecological Regions, Survey Department, ISBN 955-9059-00-9, Sri Lanka, 1988

21. Wijesekera, N.T.S., (ed in chief), "Environmental Atlas of Sri Lanka", Central Environmental Authority, Ministry of Environment and Natural Resources, Battaramulla, ISBN 955 -901231 -2, Sri Lanka, 2005 